\title{
ARROW CAUSE OF ANGINA PECTORIS: SINGLE CORONARY ARTERY ANOMALY IN ELDERLY PATIENT
}

\author{
Asl1 Göztepe ${ }^{1}$, Servet Altay ${ }^{2}$ \\ ${ }^{1}$ Trakya University School of Medicine, Edirne, TURKEY \\ ${ }^{2}$ Department of Cardiology, Trakya University School of Medicine, Edirne, TURKEY
}

\begin{abstract}
Aims: Coronary artery anomalies are rare diseases among the population. These anomalies, which are usually noticed by chance, can remain silent for many years without symptoms. We aimed to present a patient with a coronary artery anomaly without having any symptoms for many years. Case Report: A 73-year-old female patient presented to the Department of Cardiology of the Trakya University School of Medicine. The patient stated that she had chest pain that decreased with rest and increased with exercise for the last 2 months. After the cardiac examination of the patient, imaging procedures were deemed necessary. After imaging, the patient was diagnosed with a single coronary artery anomaly. The patient was recommended to have surgery, but she refused. Upon this, the patient was discharged on condition that she was kept under frequent follow-up. Conclusion: Coronary artery anomalies have reached higher rates of diagnosis thanks to increased imaging technologies in recent years. If these congenital diseases that can even cause death are noticed early, there are various treatment options. First of all, medical treatment is preferred, and surgery is recommended in patients with no response to the medical treatment. This disease, which is closely related to the patient's life, should be carefully evaluated by the doctors. Keywords: Coronary arteries, cardiac anomaly, angiography
\end{abstract}

\section{INTRODUCTION}

Coronary arteries are the vessels that nourish the heart and provide oxygen for its function. In a normal person, the coronary vessels originate from 2 main sources, right and left, and branch through the entire heart. If coronary arteries are anatomically different from normal population, it is called coronary artery anomaly. In single coronary artery cases, the right and left coronary arteries emerge from a single origin and then divide into two as of right and left, unlike the normal anatomical structure (1).

Coronary artery anomalies (CAA) are congenital defects. They are usually silent but with the development of technology, the use of coronary angiography has increased significantly. Therefore, coronary artery anomalies became more diagnosable (2).

Coronary artery anomalies are seen rarely in the population. Some of them may not cause clinical sy- mptoms, whereas some of them do start with cardiac symptoms and may lead to death.

Abnormal development of the coronary vessels in the embryonic period causes coronary anomalies. These anomalies can often remain silent for many years without any symptoms, and can sometimes be detected incidentally while investigating for other diseases (2).

According to the current data, the frequency of coronary artery anomalies vary between $0.6-1.6 \%$ (3). This wide range between the values is due to the lack of a general definition that includes the variations of the coronary artery anomalies (3). Single coronary artery anomaly is the rarest one of these anomalies and its incidence decreases to $0.024-0.44 \%$ (4).

CAA can be classified into several parameters. These are listed as the location of the right or left sinus originates from Valsalva, the anatomical distribution on the surface of the ventricle, and its relationship with the aorta and pulmonary arteries. One of the methods used

Address for Correspondence: Aslı Göztepe, Trakya University School of Medicine, Edirne, TURKEY

e-mail: aslgztp@gmail.com ORCID: orcid.org/0000-0002-9522-7130

Received: 10.11.2019 Accepted: 10.01.2020 • DOI: 10.4274/tmsj.galenos.2020.07.01.06 Available at: tmsj.trakya.edu.tr

Cite this article as: Göztepe A, Altay S. Arrow cause of angina pectoris: single coronary artery anomaly in elderly patient. Turkish Med Stud J 2020:7(1);34-6. 
in the angiographic classification of CAA is Modified Lipton Classification (5).

Approximately $40 \%$ of the single coronary artery anomaly (SCAA) cases are seen with other cardiac anomalies. The most common of these have been reported as congenital heart diseases such as Fallot tetralogy, pulmonary atresia, persistent truncus arteriosus and transposition of the great arteries (4).

SCAA rarely presents with symmptoms such as myocardial ischemia, angina, syncope, and myocardial infarction. These symptoms may not be diagnostic for SCAA, but they direct us towards SCAA (6).

Apart from the anomaly, the patient's concomitant cardiac and non-cardiac diseases, lifestyle and daily activities shape the clinical course and prognosis of CAA.

We aim to present a case report regarding a patient with a coronary artery anomaly and contribute to the literature because of its rareness and potential death risk.

\section{CASE REPORT}

A 73-year-old female patient applied to the cardiology department of Trakya University School of Medicine with the complaint of chest pain that appears with effort and decreases while resting for the last 2 months. The first medical approach was electrocardiography (ECG) to determine our patient's medical condition. No abnormalities were detected on ECG. Additionally, the patient was evaluated by using an echocardiogram. In the echocardiogram, the ejection fraction value of the patient was $62 \%$. In addition, the inferior wall was detected mildly hypokinetic. After these findings, it was necessary to perform coronary angiography. In the imaging, it was seen that the entire coronary system of the patient's heart was originated from the right coronary artery. However, no stenosis was observed in the vessels. For further examination, the patient also had a computerized tomography coronary angiogram. In the imaging, the left main coronary artery was seen between the aorta and the right ventricular outflow tract (Figure 1,2).

After the evaluation, the option to have surgery was offered to the patient, but she did not accept the surgery. Upon this, the patient was prescribed $50 \mathrm{mg}$ of metoprolol, $20 \mathrm{mg}$ of atorvastatin, $20 \mathrm{mg}$ of acetylsalicylic acid. After the treatment, doctors decided to keep the patient under supervision with regular visits. Lastly, the patient was informed about the risks and she was discharged.



Figure 1: Coronary angiography view: Right oblique window (RCA: Right coronary artery, LAD: Left artery descending, CX: Circumflex).

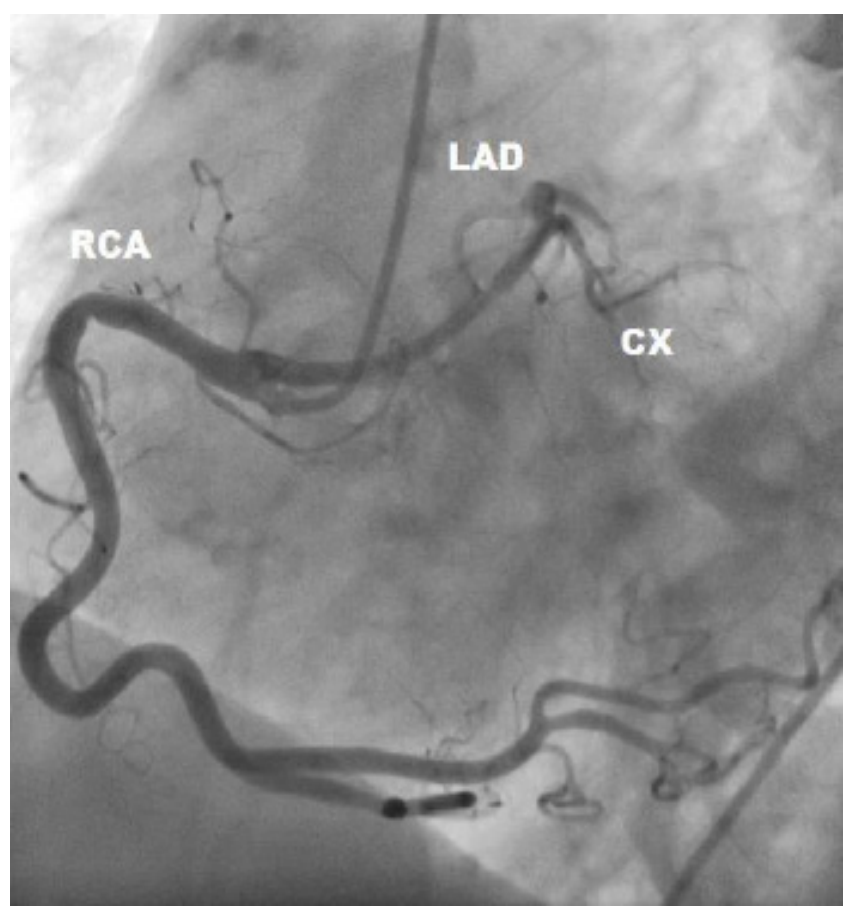

Figure 2: Coronary angiography view: Left oblique window (RCA: Right coronary artery, LAD: Left artery descending, CX: Circumflex). 


\section{DISCUSSION}

The incidence of CAA varies depending on the sources. Çayhan et al. (7) stated the range is between 0.2-1.2 . Although these anomalies are seen rarely, there are cases in the literature that cause myocardial dysfunction, infarction, syncope, angina and sudden death $(7,8)$.

Patients with CAA are generally detected incidentally and do not differ significantly from normal hemodynamic parameters. However, CAA with an ectopic origin and passing through the aorta and pulmonary arteries have a higher potential to cause myocardial ischemia and even sudden death (2).

Coronary artery anomalies can basically be divided into 3 main categories. These are exit anomalies, cruise anomalies, and termination anomalies. It is possible to divide these 3 types into subtypes. There is not a certain classification in the literature thus there are different perspectives in many articles $(2,3)$. Our case falls under the coronary exit anomaly category because of its anatomical structure. It is possible to classify the coronary artery exit anomalies into 3 groups according to the osteal location and the number of ostia $(2,3)$.

In our case, the entire coronary system originates from the right coronary artery. In other words, the left main coronary artery originates from the sinus of Valsalva.

Usually, many types of CAA's do not have life-threatening complications. They may remain silent for many years and even may not cause symptoms until the end of life. The fourth type, unlike the others, has a risk of angina, myocardial infarction and sudden cardiac death. Due to these risks, surgical treatment is recommended for type 4 patients (5).

Arrhythmogenic right ventricular dysplasia and hypertrophic cardiomyopathy are accepted as the most common causes of sudden cardiac death and coronary artery anomalies are the third right after them (3). Although Güven et al. (4) indicate that the coronary artery anomalies are one of the reasons for sudden cardiac death at a young age, our case is 73 years old and has not shown any life-threatening symptoms like angina or dyspnea until this time.

Early diagnosis and drawing a road map according to the anatomical structure of the anomaly are the golden steps in the treatment process. In diagnosis, conventional cardiac angiography is accepted as the gold standard. However, in recent years, computerized tomography coronary angiogram has been the most used and recommended method due to its definitive diagnostic ability (3).
Symptomatic patients are mostly related to the size of myocardial tissue at risk and the character of the anatomy (4-6).

As a conclusion, CAA can be very serious and remain silent for years. These congenital anomalies, which can affect the patients' quality of life and cause them to die at a younger age, should not be overlooked in patients with compatible cardiac symptoms.

\section{Ethics Committee Approval: N/A}

Informed Consent: Informed consents were obtained from the patient for this study.

Conflict of Interest: The authors declared no conflict of interest.

Author contributions: Concept: AG, SA. Design: AG, SA. Supervision: AG, SA. Materials: AG, SA. Data collection and/or processing: AG, SA. Analysis and/or Interpretation: AG, SA. Literature Search: AG, SA. Writing Manuscript: AG, SA. Critical Review: AG, SA.

Financial disclosure: The authors declared that this study received no financial support.

Editor-in-chief's Note: One of the authors of this article, Aslı Göztepe is a member of the editorial board of Turkish Medical Student Journal. However, she did not take place in any stage on the editorial decision of the manuscript. The editors who evaluated this manuscript are from other institutions.

\section{REFERENCES}

1. Sharma B, Chang A, Red-Horse K. Coronary artery development: Progenitor cells and differentiation pathways. Annu Rev Physiol 2017;79:1-19.

2. Göldeli Ö, Badak Ö, Kırımlı Ö. Tek koroner arter: Olgu sunumu. Turk Kardiyol Dern Arş 1999;27:647-51.

3. Çelik A, Doğdu O, Özdoğru İ et al. Single coronary artery. Turk Kardiyol Dern Ars 2009;37(8):591.

4. Güven A. Single coronary artery anomaly: A report of two cases. Turkiye Klinikleri J Cardiovasc Sci 2013;25(2):84-7.

5. Başar N, Akpınar İ, Turak O et al. Frequency of isolated single coronary artery anomalies during conventional coronary angiography. Selçuk Ünv Derg 2011;27(3):137-41.

6. Kandemir H, Alp Ç, Karadeniz M et al. Tek koroner arter çıkış anomalisi: Olgu sunumu. Ortadoğu Tip Dergisi 2018;10(2):205-8.

7. Çayhan B, Taş S, Saçlı H et al. Koroner arter anomalili bir olguda cerrahi tedavi. Kosuyolu Kalp Dergisi 2014;17(1):76-8.

8. Alpsoy Ş, Akyüz A, Akkoyun D et al. Sağ sinüs valsalvadan çıkan sol ana koroner arter anomalisi. Kocatepe Tip Dergisi 2016;17(1):1-4. 